\title{
A família na unidade de internação hospitalar: entre o informal e o instituído*
}

FAMILIES IN THE OVERNIGHT STAY UNIT OF THE HOSPITAL:
BETWEEN INFORMAL AND INSTITUTED

\author{
LAFAMILIAEN LA UNIDAD DE INTERNAMIENTO HOSPITALARIO: \\ ENTRE LO INFORMAL Y LO INSTITUIDO
}

Marisa Monticelli', Astrid Eggert Boehs ${ }^{2}$

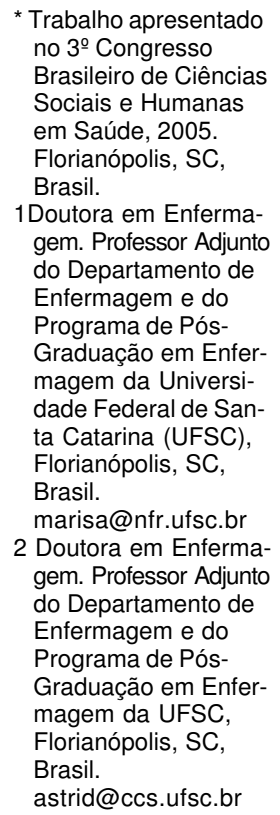

1Doutora em Enfermagem. Professor Adjunto do Departamento de Enfermagem e do Programa de PósGraduação em Enfermagem da Universidade Federal de Santa Catarina (UFSC), Florianópolis, SC, Brasil.

marisa@nfr.ufsc.br

2 Doutora em Enfermagem. Professor Adjunto do Departamento de Enfermagem e do Programa de PósGraduação em Enfermagem da UFSC, Florianópolis, SC, Brasil.

astrid@ccs.ufsc.br

\section{RESUMO}

Estudo de abordagem comparada que utilizou duas etnografias já concluídas com o objetivo de identificar como as famílias percebem suas inserções na unidade de internação e como são percebidas pela equipe de saúde, considerando-se as regras e as normas da cultura institucional. Os resultados obtidos revelam que tanto as equipes quanto as famílias se aproximam ou se distanciam em face da concordância ou não das regras vigentes na instituição. Embora as famílias, em muitas situações, submetam-se aos regulamentos impostos pelo hospital e pela equipe, também usam resistências individuais e coletivas para enfrentar os mecanismos reguladores. Os resultados contribuem para aumentar a compreensão sobre o tema, tanto para a equipe de saúde quanto para a prática de enfermagem com famílias, especialmente no sentido de reconhecer as famílias como unidades ativas, responsáveis e co-participantes na atenção intra-hospitalar.

\section{DESCRITORES}

Família.

Hospitalização.

Enfermagem familiar.

Saúde da família.

\section{ABSTRACT}

This study uses a comparative approach, as well as two already concluded ethnographies, to achieve its objective of identifying how families perceive their insertion into the overnight stay unit in a hospital and how they are perceived by the health care team, considering the rules and regulations of the institutional culture. The results obtained show that teams and families get closer or more distant depending on whether there's agreement or disagreement regarding the hospital's governing rules. Although families, in many situations, subject themselves to the regulations imposed by the hospital and the health care team, they also use individual and collective resistances in order to confront the regulatory mechanisms. The results contribute to increase the comprehension of this theme, both for the health care team and for the practice of family nursing, especially in the sense of recognizing the family as an active, responsible, and co-participatory unit within intra-hospital care.

\section{KEY WORDS}

Family.

Hospitalization.

Family nursing.

Family health.

\section{RESUMEN}

Un estudio de abordaje comparado que utilizó dos etnografías ya concluidas con el objetivo de identificar como las familias perciben sus inserciones en la unidad de internamiento y como éstas son percibidas por el equipo de la salud, considerándose las reglas y las normas de la cultura institucional. Los resultados obtenidos revelan que tanto los equipos cuanto las familias se aproximan o se distancian en torno del acuerdo o no de las reglas vigentes en la institución. Aunque, las familias en muchas situaciones, se sometan a los reglamentos impuestos por el hospital y por el equipo, también, usan resistencias individuales y colectivas para que ellos enfrenten los mecanismos reguladores. Los resultados contribuyen para aumentar la comprensión sobre el tema, tanto para el equipo de la salud, cuanto para la práctica de la enfermería con las familias, especialmente, en el sentido de reconocer a las familias como unidades activas, responsables y co-participantes en la atención intrahospitalar.

\section{DESCRIPTORES}

Familia.

Hospitalización.

Enfermería de la familia.

Salud de la familia. 


\section{INTRODUÇÃO}

A presença de um membro da família que acompanha o cliente em unidades de internação está cada vez mais freqüente, tanto no âmbito da assistência à criança e adolescente, quanto em maternidades, sendo que, mais recentemente, com a aprovação do estatuto do idoso, isto está sendo uma realidade também nesta faixa etária. Tal exigência, fortemente marcada pelos movimentos sociais e requisitada pelos ativistas dos direitos de saúde dos cidadãos brasileiros, dentre esses, muitos profissionais da área, tem posto em relevo as demandas necessárias ao pleno funcionamento da dinâmica das internações hospitalares, especialmente no que diz respeito às relações culturais que se estabelecem entre os cuidadores profissionais e as famílias, que também cuidam e se envolvem de diversas formas com a pessoa internada. Algumas dessas demandas dizem respeito, diretamente, aos conhecimentos e aos valores que a equipe de saúde e particularmente a equipe de enfermagem possuem sobre as famílias que cuidam e que ajudam a cuidar, dentro das instituições hospitalares.

Um olhar mais atentivo, no entanto, revela que não é inteiramente nova esta preocupação. A literatura tem sido reiterativa em mostrar a importância deste tema, seja para a discussão da satisfação da família com relação à assistência, seja para avaliar que tipo de interação é estabelecida entre familiares acompanhantes e membros da equipe de saúde ${ }^{(1-8)}$. Ainda que alguns destes estudos ${ }^{(5-6)}$ tenham utilizado abordagens teóricas fundamentadas nos aspectos antropológicos, entretanto, não avançam nos aspectos dos poderes e das forças culturais que permeiam as relações da equipe com os familiares acompanhantes, dentro do locus hospitalar, principalmente no que diz respeito à inserção da família neste cenário e às permissões e normalizações que são estabe-lecidas no dia-a-dia dos processos de admissão, permanência e altas das unidades de internação.

O desenvolvimento recente de duas etnografias (já concluídas) realizadas em cenários assistenciais diferenciados, porém ambas envolvendo crianças e suas famílias ${ }^{(9-10)}$, indica algumas similaridades e diferenças no modo como as famílias convivem e lidam com as regras institucionais e com os profissionais da equipe, bem como no modo como a própria equipe interpreta os movimentos das famílias, envolvendo-se e convivendo com as mesmas em meio a prescrições e regras, durante o período da internação. Interpretamos esses modos de agir como sendo formas que a família encontra para se inserir no hospital e, igualmente, de a equipe inseri-la no cenário institucional, considerando-se que ambas as perspectivas são adotadas de acordo com as teias de significados ${ }^{(11)}$ imersas na cultura das famílias e das ins- tituições hospitalares. Ao compararmos estas duas etnografias, buscamos responder à seguinte questão: como as famílias nestes dois estudos se inserem e são inseridas pelas equipes de profissionais em cenários assistenciais de hospitais públicos? O objetivo é identificar como as famílias percebem suas inserções na unidade de internação e como são percebidas pela equipe de saúde, considerandose as regras e as normas da cultura institucional.

\section{MÉTODO}

A metodologia comparada foi eleita para a organização e análise dos dados provenientes das duas etnografias consultadas. Embora cada etnografia tenha abordado distintos cenários clínicos (uma unidade de internação pediátrica e uma unidade de alojamento conjunto), ambas trabalharam com famílias em ambiente hospitalar e adotaram fundamentos teóricos culturais para a coleta e interpretação dos dados. O fato de ambas terem sido desenvolvidas pelas mesmas autoras do presente estudo, também foi justificativa para usá-las como mapa de dados.

Este tipo de metodologia tem sido utilizado pela Antropologia desde os seus primórdios, a ponto de se considerar a Antropologia como 'o ponto de vista comparativo'. Geralmente ela é concebida como a comparação de semelhanças e diferenças entre grupos, sociedades ou partes delas entre $\mathrm{si}^{(12)}$. Diversos autores têm considerado que a abordagem comparada é uma valiosa ferramenta de investigação para analisar dados qualitativos, sendo tipicamente empregada por pesquisadores que coletam dados através da observação participante e da entrevista ${ }^{(13-16)}$, como foi o caso das técnicas de obtenção de dados utilizadas nas etnografias que estamos considerando como sendo as fontes de onde se originam os dados para responder à pergunta da presente pesquisa.

Para seguir os princípios gerais indicados pela metodologia comparada optamos por tecer associações por similaridades e contrastes, através da reflexão exaustiva sobre o mapa de dados advindo das etnografias consultadas. Assim, por exemplo, ao identificarmos que em uma determinada unidade de internação as famílias utilizavam-se de expedientes singulares para burlar algumas normas estabelecidas pela instituição hospitalar, e que em outra unidade também haviam atitudes parecidas, ao focalizarmos outras famílias, nosso esforço analítico concentrava-se então em torno de associações aproximativas quanto aos significados impressos nas atitudes das famílias, buscando enquadrar este recorte em alguma categoria representativa. Em suma, os passos que compuseram a metodologia consistiram-se basicamente em organizar paulatinamente os dados semelhantes 
ou contrastantes, classificando-os em categorias e, à medida que as categorias iam se tornando cada vez mais explícitas, era então possível constituir regras para incluir termos ou títulos mais amplos que englobassem tais categorias ${ }^{(12)}$, conforme descreveremos a seguir, na discussão dos resultados. Contudo, para que o leitor possa ter uma visão geral dos dois estudos que forneceram os dados para esta comparação, realizamos uma identificação sucinta dos mesmos.

O primeiro, denominado de etnografia $A^{(9)}$, foi desenvolvido numa unidade de internação pediátrica de um hospital infantil público, tendo como sujeitos treze familiares acompanhantes das crianças ali internadas, bem como quinze componentes da equipe de saúde da unidade. Os objetivos foram de compreender as percepções da equipe acerca da presença da família e seu cuidado à criança e compreender como a família e a enfermagem realizam o cuidado na unidade de internação. Utilizou a observação participante como técnica principal de coleta de dados e a entrevista etnográfica como técnica complementar. As observações envolveram as interações cotidianas entre os profissionais e as famílias dentro da unidade procurando, dentro do possível, não perturbar o ritmo normal de trabalho da equipe nem dos familiares, uma vez que o objetivo era conhecer como o cuidado era desenvolvido, em seu ambiente natural. As entrevistas não estruturadas aconteceram no cotidiano, durante as observações. Inicialmente, de forma mais abrangente e, posteriormente, foram se tornando mais focadas ${ }^{(17)}$. Os procedimentos analíticos dos dados coletados envolveram o agrupamento de domínios, buscando nestes alguns temas culturais $^{(17)}$ que responderam aos objetivos do estudo. A pesquisadora permaneceu oito meses desenvolvendo o trabalho de campo.

O segundo, denominado de etnografia $B^{(10)}$, foi desenvolvido em uma unidade de alojamento conjunto (onde as puérperas, os recém-nascidos e os familiares acompanhantes permanecem, desde o pós-parto imediato, até a volta para casa) de uma maternidade pública do sul do Brasil. Os sujeitos da pesquisa foram quarenta e dois familiares acompanhantes das puérperas internadas naquela unidade e também dezenove membros da equipe de saúde, sendo a maioria integrante da equipe de enfermagem, por serem estes os profissionais que têm maior interlocução com as famílias. $\mathrm{O}$ objetivo foi o de compreender o universo cultural que permeia as relações entre a equipe e as famílias que se encontram internadas no alojamento conjunto. Os guias para levantamento de dados envolveram a utilização de observações e entrevistas, similares ao desenho da etnografia A, utilizando-se roteiros específicos, tanto para desenvolver as observações participantes, quanto as entrevistas com os familiares e os profissionais da equipe ${ }^{(18)}$. Os procedimentos analíticos da pesquisa tiveram seus fundamentos nas orientações da etnoenfermagem ${ }^{(18)}$, buscando responder aos objetivos propostos. O trabalho de campo teve duração de doze meses.
Ambas as etnografias cumpriram com os requisitos éticos exigidos pela Resolução 196/96 do Conselho Nacional de Saúde ${ }^{(19)}$ e tiveram seus projetos autorizados por Comitê de Ética em Pesquisa com Seres Humanos.

\section{RESULTADOS E DISCUSSÃO}

\section{Como a família entra e sai da instituição: admissão e alta}

O modo como as famílias dão entrada nos dois hospitais oferece um panorama simbólico para compreender o grande peso que as instituições formais de saúde ainda imputam sobre as mesmas. No hospital pediátrico apenas a criança e algum outro familiar acompanhante vêm para o local da internação, havendo fortes entraves normativos que impedem o comparecimento de mais de um integrante da família num mesmo período, mesmo que esse seja um desejo fortemente explicitado pela família da criança. Muitas vezes o pai e a mãe requerem a entrada conjunta na unidade, porém tal requerimento é rapidamente indeferido pela equipe, sob o argumento de que a norma é da entrada de apenas um acompanhante. O que se percebe é que, com tais regulamentos, a unidade familiar é reduzida, perdendo a autonomia para permanecer integrada, o que exige uma reorganização de sua própria dinâmica interna para dar conta do processo de internação. No cenário da maternidade a situação não é diferente, pois desde que a puérpera e o recém-nascido saem do centro obstétrico em direção ao alojamento conjunto, somente mais um integrante da unidade familiar tem a permissão para acompanhar.

Logo que as famílias dão entrada nas unidades, seguemse os ritos de admissão, que regulam a passagem de fora para dentro do hospital. Na unidade pediátrica, a primeira providência é a identificação da cama e algumas orientações ao acompanhante sobre procedimentos para sua acomodação. Segundo um componente da equipe de enfermagem: $a$ gente vai orientando aos poucos, para não confundi-los. No alojamento a família é recebida em quartos coletivos (o alojamento conjunto é composto por cinco desses grandes quartos) e que comporta em torno de oito a nove díades mães-bebês, além dos familiares acompanhantes. É regra geral que as famílias não devam escolher o leito que desejam permanecer. A ocupação do leito e do berço é determinada unicamente pela vaga disponível, não tendo a família qualquer chance de escolha, seja do quarto, do leito ou do berço. Além disso, à puérpera é solicitado que ocupe o leito com brevidade, sem que se tenha o cuidado com as apresentações às outras companheiras de quarto ou às dependências da unidade. Este descuido da equipe leva ao retraimento das famílias, retardando o processo comunicacional entre elas, e demandando esforços extras para dar conta de situarem-se espacialmente na unidade.

Tomando-se o processo de admissão como um conjunto de procedimentos e operações que podem reduzir a pessoa 
à doente ${ }^{(20)}$, é possível refletir que a separação do mundo externo é praticada em ambas as instituições. Porém, na unidade pediátrica em foco, há maior preocupação em promover algumas medidas (como por exemplo, resguardar a família da massificação de informações, logo na chegada) que contribuem para tornar mais leve o peso da instituição total $^{(21)}$, ou seja, atitudes que, mesmo sendo pontuais, têm a intenção de manter a dignidade das pessoas, enquanto indivíduos integrais e não apenas na condição de doentes internados $^{(20)}$. Neste modo de atuar estão envolvidos diversos fatores contributivos, que dizem respeito tanto à implantação distinta de programas de humanização da assistência nessas instituições, quanto às características inerentes ao tipo de usuários que recebem e o tempo de internação que decorre entre a admissão e a alta, que é diferente nas duas instituições.

O modo como a família recebe alta das instituições também revela símbolos e significados que visam marcar socialmente a transição para o mundo de dentro e o retorno (ou liberação $o^{(21)}$, no sentido da desvinculação do jugo da instituição) ao mundo de fora do hospital. Assim, na unidade pediátrica, logo após ter assinada a alta (prerrogativa médica), a família da criança recebe explicações sobre os cuidados a serem realizados no domicílio e a equipe realiza os trâmites burocráticos realizados na própria unidade, após a criança se retirar daquele local. No alojamento a alta também é de decisão médica. Enquanto o neonatologista oficializa a liberação da criança, o obstetra formaliza a da puérpera. Essa dinâmica, bastante genuína em termos institucionais, leva muitas vezes a descompassos não somente entre as especialidades da biomedicina (neonatologia e obstetrícia), mas também entre a família e a instituição, uma vez que nem sempre o recémnascido e sua mãe apresentam coincidências clínicas que promovam a alta conjunta. Enquanto para as famí-lias da unidade pediátrica a alta se dá sem um marcador sim-bólico especial, as que estão saindo do alojamento conjunto devem participar da palestra de alta - condição indispensável para a liberação definitiva do jugo institucional.

\section{$O$ (a) acompanhante: preferências e requisitos de escolha}

Seja no hospital pediátrico ou na maternidade, a figura do familiar acompanhante é entendida como aquela que permanece ao lado do internado, fornecendo apoio emocional, mas também auxiliando nas tarefas que apresentam íntima relação com as rotinas desenvolvidas no ambiente doméstico. Entretanto, o contexto de permanência do familiar na unidade varia, em termos de preferências, requisitos e performances, a depender de quem realiza a escolha, se os profissionais ou as famílias. Quanto às preferências sobre quem será o familiar acompanhante, percebe-se que existe um certo consenso entre a decisão da enfermagem e da família no hospital pediátrico, embora haja a constatação da equipe de que as mães têm mais jeito para cuidar do que os pais - sendo, portanto, as preferidas para acompanhar as crianças internadas - geralmente a equipe aguarda a decisão dos próprios familiares, uma vez que o processo de institucionalização é, na maioria das vezes, bastante longo, em vista das condições clínicas da criança, necessitando então de revezamento com os demais membros da família.

Quanto ao alojamento conjunto, a equipe revela a preferência pelas mulheres como acompanhantes, na seguinte ordem de prioridade: mãe da puérpera, sogra, irmã, ou outras mulheres -, enquanto as famílias, muitas vezes, preferem homens acompanhantes (quase sempre o pai do bebê). Sob a perspectiva da escolha do acompanhante no interior das próprias famílias, constata-se que as mesmas também dão preferência a outras mulheres (na mesma lista de prioridades da equipe), consideradas mais experientes, o que apresenta aderência com outros estudos já realiza$\operatorname{dos}^{(22-23)}$, mas quando decidem por um homem, percebem a resistência explícita ou velada da equipe, que argumenta e insiste para que seja uma mulher a acompanhar, principalmente no período noturno, onde, segundo os profissionais da enfermagem, as demandas de cuidados são mais freqüentes.

As preferências da equipe e das famílias na unidade de internação infantil recaem sobre a pessoa que tenha os requisitos de experiência de cuidado àquela criança, que implica levarem-se em conta certas afinidades entre o familiar acompanhante e a criança; e ter paciência. A partir daí vão então ocorrendo os revezamentos, que podem envolver tias, pais, mães, avós, e ainda mobilizar outros membros da família extensa que residem na cidade ou fora dela. No entanto, os dados do estudo também mostram conflitos: a tia que permanece, porque julga que a mãe da criança não cuidou direito; o pai biológico que é obrigado pela mãe a ficar, para que assuma sua responsabilidade de pai; o pai afetivo (companheiro da mãe) que é requisitado para revezar com o pai biológico, para que assim, mostre que realmente assume sua função de pai que diz ter.

Quanto aos requisitos de escolha do acompanhante, do ponto de vista da equipe, na maternidade, a opção pelas mulheres experientes da família é feita devido ao vínculo físico e simbólico representado pelo papel feminino. Aqui, ao invés de ser colocada em pauta a capacidade da mulher para cuidar, como ocorre na unidade pediátrica, é ressaltada a incapacidade do homem para cuidar de mulheres que acabaram de dar à luz e de crianças que acabaram de vir ao 
mundo. Além disso, os homens acompanhantes constrangem as demais puérperas, dormem demais e não têm a 'capacidade feminina' de ficarem atentos às necessidades da puérpera e do recém-nascido.

Para as famílias que escolhem outras mulheres como acompanhantes não há conflitos; no entanto, quando é sobre os companheiros (pais dos bebês) que recai a preferência, o argumento é de que o mesmo precisa assumir com a maior brevidade o papel de pai e papel de marido, levando ao início da operacionalização do ideário da família grávi$\mathrm{da}^{(24)}$ e favorecendo a iniciação do trio, no seio da família nuclear $^{(25)}$.

\section{A permanência da família na instituição: prescrições $e$ resistências}

Durante o processo de internação, e independente do tempo que a família permaneça no hospital, ela está sempre envolvida no jogo entre aquilo que é instituído e aquilo que, de algum modo - mais sorrateiro ou mais explícito - pode ser transcendido. $\mathrm{O}$ mesmo pode ser afirmado quando o foco é dirigido para a equipe de saúde e, especialmente, para a equipe de enfermagem.

\section{O entra e sai dos (as) acompanhantes}

Com relação às regras a serem seguidas para a permanência do familiar acompanhante, o cotidiano da internação na unidade pediátrica revela-se criativo e envolto em tensões. Diante das normas do hospital que impedem a permanência de mais de um familiar acompanhante junto à criança durante a internação, conforme já referido anteriormente, as observações realizadas mostram que há quase sempre um clima de insistência para que ambas as partes da família (a que está fora do hospital e a que está dentro), se revejam e se encontrem durante um tempo maior do que aquele préestabelecido pela instituição, já que o regulamento prevê que a troca de acompanhantes ocorra somente durante meia hora, em cada um dos três períodos do dia, no espaço da portaria de entrada de visitantes, no andar térreo do hospital. Como nem sempre a família consegue seguir os preceitos, diante de horários e comportamentos tão rígidos, e também porque deseja uma comunicação mais informal, utilizase então muitas vezes de determinadas estratégias para burlar as regras, tais como a conversa sorrateira entre o acompanhante que chega e o que sai, por meio da janela da unidade ou então ousa um pouco mais, de acordo com a conveniência, afirmando ao porteiro que conhece o diretor, visando o benefício da entrada, ou ainda joga o crachá pela janela para que a pessoa que está fora possa entrar e a troca ocorrer na unidade de internação.

Sobre a permanência do familiar no alojamento conjunto da maternidade, salvo as puérperas adolescentes, às demais, a troca de acompanhantes é permitida somente até o início da noite. Logo que ocorre a entrada da puérpera e do recém-nascido na unidade, ao familiar acompanhante é informado, por escrito e oralmente, as normas e rotinas que regulamentam sua estadia na unidade, envolvendo: permanecer na cadeira, não fazer a cama no chão, não falar alto, não olhar para as companheiras de quarto da puérpera (no caso de acompanhante homem), entre várias outras normas. Diante de tantas recomendações, a maioria dos familiares apresenta reações de conformidade e/ou concordância com as regras, tais como: não se preocupem que eu não vou fazer nenhuma besteira; seguidas de reações demonstrativas de submissão ao papel de bom acompanhante. Entretanto, embora menos comuns, as reações de resistência às regras estabelecidas também têm lugar entre as famílias do alojamento, como por exemplo: encostar a cadeira no leito da puérpera para tirar um cochilo ou dormir à noite, e andar descalço pelos corredores.

\section{A vivência diária entre as normas e suas transcendências}

Considerando-se o dia-a-dia do período de internação, vários aspectos podem ser levantados no que se refere à dinâmica entre prescrições e resistências. Na unidade pediátrica, por exemplo, essa dinâmica é bem marcada naquilo que diz respeito às necessidades de descanso das famílias no interior do hospital. Na hora de dormir, procurase, por todos os meios, tornar a cadeira mais confortável, forrando-a com um cobertor ou utilizando uma cadeira vazia para apoiar os pés, mas nem sempre isso está de acordo com as normas estabelecidas para o funcionamento da unidade $\mathrm{e}$ conservação dos móveis, e a equipe de enfermagem flagra estes expedientes fortuitos. Algumas amizades conquistadas com o pessoal da unidade, entretanto, favorecem determinados ganhos que têm relação direta com a frouxidão das normas. As famílias que vêm do interior, as que se encontram há bastante tempo na unidade e as que têm crianças com doenças crônicas são as que conseguem burlar as normas com maior freqüência, sob certa aquiescência da equipe.

No alojamento conjunto o jogo entre o informal e o instituído é sempre dinâmico e conflitual. Às vezes mesmo, de acordo com a equipe, é necessário transcender as normas. Os procedimentos executados que se sobrepõem à norma são variados e não se constituem propriamente em ações rotineiras e despropositadas, pelo contrário, são desenvolvidas com a clara intenção de ajudar a promover maior conforto e bem-estar. Dentre estas práticas destacam-se a complementação - a prática de alimentar a criança com outro leite, que não o da mãe, no intervalo das mamadas - e o uso da chupeta pela criança recém-nascida.

Mais do que simplesmente com a intencionalidade de quebrar as regras ou explicitamente burlar as normas, enfermagem e famílias agem transcendendo/transpondo as normas. Atuam num pacto quase silencioso, buscando ir além 
do instituído, com a intenção de dar conta da complexa demanda assistencial da unidade. Assim como não desconhecem as informações, proibições e recomendações oficiais, equipe e famílias não são ingênuas em termos do reconhecimento dos poderes instituídos dentro da maternidade. Não é por coincidência que essas práticas são noturnas, já que à noite, segundo um médico, todos os gatos são pardos, isto é, as fiscalizações e vigílias formais são menos intensas e, portanto, abre-se espaço para o não instituído, onde as normas regimentais podem ser transpostas em comum acordo entre equipe e famílias. É como se à noite houvesse a organização de um modus vivendi próprio, resistente a regras formais e temporalmente mais poroso a justificativas que permitam construções e reconstruções de algumas normas advindas da experiência compartilhada entre equipe e famílias.

Ainda que, por vezes, para fazer frente à complexidade da assistência, seja necessário transcender às regras, é importante assinalar que a equipe não se afasta em demasia dos estatutos estabelecidos pelos programas formais de incentivo à amamentação e nem mesmo se descuidam completamente de suas responsabilidades relativas ao exercício profissional e atuação clínica. De algum modo essas práticas são geralmente tácitas, mas não se pode afirmar que estejam totalmente à margem do instituído. A prática da complementação é um bom exemplo disso.

Esse contexto nos leva a argumentar que dentro do hospital como instituição total ${ }^{(21)}$, despontam organizações prosaicas que envolvem os internados e os 'de dentro', denominadas de zonas francas ou refúgios ${ }^{(21)}$ que contemplam não só o que a instituição espera que ambos façam do seu cotidiano, mas também do que não está regularizado e que funcionários e internados exploram ao mínimo pormenor, para humanizar o ambiente e preservar o eu individual ${ }^{(21)}$. Considerando-se as práticas da chupeta e da complementação, adicionaríamos que tais zonas francas somente são criadas porque ressurgem das experiências conjuntas e negociadas entre a equipe e as famílias, o que por sua vez, se constituem em lubrificadores do funcionamento da estrutura formal e que consubstanciam a estrutura informal da instituição ${ }^{(20)}$. As zonas francas são práticas empregadas que permitem aos participantes do cuidado suportar as imposições que a realidade lhes apresenta.

Este contexto nos remete à maneira como as instituições pensam $^{(26)}$, já que se sabe que em situações difíceis, de crise, a instituição se vê quase que obrigada a deixar de lado seu conjunto regular de princípios organizacionais e morais e adota um conjunto regular de emergência que não é revogação de todos os princípios, ou seja, não se trata de colapso total das convenções (necessárias ao funcionamento institucional), mas de certa forma, protege as pessoas, durante um lapso de tempo, até que retornem aos padrões originais convencionados oficialmente ${ }^{(26)}$. Cremos que existe um paralelo entre esta estratégia e as práticas que transcendem às normas prescritas no alojamento, uma vez que o estresse provocado pelo choro do bebê e a experiência nem sempre sublime das mães quanto ao aleitamento, acabam por fazer com que se negociem outros conjuntos regulares de emergência que, provisoriamente, diminuem o tensionamento e de certo modo preservam abertos os canais de comunicação e interação entre a equipe e as famílias. Assim, a aceitação de ambos os lados testemunha a não a destruição da ordem social, mas sua afirmação $o^{(26)}$.

\section{Redes de solidariedade}

Na vivência das famílias nas instituições observamos algumas relações que são entendidas, tanto no contexto da unidade pediátrica, quanto do alojamento conjunto, como redes de solidariedade. Estas redes funcionam como importante sistema de apoio para os familiares acompanhantes, tornando mais interativo e menos regulamentado o processo de internação.

As redes de solidariedade se formam dentro do hospital pediátrico através da identificação entre os integrantes das famílias, em que cada acompanhante que chega é acolhido e envolvido com simpatia e interesse pelos demais que já estão na unidade de internação. Esta rede de solidariedade poderia ser denominada como a família de dentro, e possui duas formas de ajudar; primeiro, atendendo às necessidades dos próprios familiares acompanhantes, de forma que são os (as) companheiros (as) de quarto que vão passando, passo a passo, a maneira de sobreviver dentro da unidade. Trocam experiências sobre como evitar problemas com a equipe, discutem as regras a serem seguidas, pedem para olhar a criança e assim terem a possibilidade de atenderem suas próprias necessidades. Além disso, outra forma de ajudar é envolver-se diretamente nos cuidados, orientando o (a) companheiro (a) sobre como acalmar a criança quando são realizados procedimentos dolorosos ou chamando alguém da equipe quando há uma emergência. A força desta família de dentro é sutil, não declarada; às vezes bem aceita pela equipe, às vezes rejeitada por tornar-se um complô que pode estimular e dar força para quem está chegando e para quem ainda não tem experiência. Esta família de dentro exerce pressão velada pelos direitos dos familiares, tornando a vida menos árdua neste espaço instituído.

Podemos dizer que na maternidade as redes de solidariedade são formadas entre as puérperas que estão vivenciando o mesmo processo, muitas vezes com a formação de círculos de conversa entre os leitos ou qualquer pequeno espaço que esteja livre. A conversa ocorre de modo rápido, onde trocam informações, compartilham conhecimentos trazidos de casa, discutem meios de cuidar de si e do bebê, reúnemse para enfrentar o marido daquela mãe considerada desprotegida, conversam sobre os filhos que ficam em casa e oferecem o ombro para aquela que perdeu o bebê ou está com o filho doente. 
No alojamento existe um lugar para o florescimento de diálogos interfamiliares que deixa transparecer um locus criativo de resistência ao conhecimento médico institucionalizado, ao sistema normativo do hospital e, ao mesmo tempo, uma rede de intercâmbio que reafirma os saberes e as práticas do setor familiar de cuidado à saúde, dentro do cenário clínico. Este círculo de comadres funciona com uma espécie de cenário seguro para que sejam contrapostas as desavenças e abalizadas as consequiências das tomadas de decisões diante da realidade clínica do alojamento conjunto. Para estas famílias o espaço gerado tem uma postura de não passividade frente aos ditames do hospital e dos saberes que regem as regras a que, em grande número de casos, precisam se submeter.

As redes de solidariedade nos dois hospitais formalizam um interapoio e se fortalecem frente à instituição, onde intimidades são compartilhadas. Isto fica claro na fala de uma familiar acompanhante do alojamento: aqui se pega amizade.

\section{O olhar da equipe sobre a familia e o olhar da familia sobre a equipe}

Nos cenários de cuidado em pauta é comum a equipe utilizar procedimentos informais para o levantamento de dados sobre as famílias, suas tipologias, constituições e suas organizações para o cuidado ao internado:

só de olhar a gente vê o jeito que elas (as mães) cuidam ... não sei explicar muito, quando interna uma criança nova, vou lá no quarto, olho, converso e vou observando se aquela mãe é mais estressada ou mais quieta (Auxiliar de Enfermagem).

Tanto na unidade pediátrica como no alojamento, mesmo que a equipe se refira ao termo família com freqüência e certa regularidade, o que se constata, por meio de seu modo de interação e pela forma de comunicação que utiliza, é que ela vê apenas a figura do familiar acompanhante. Assim, apesar do esforço recente, principalmente da academia, de considerar a família como cliente do cuidado de enfermagem, a equipe ainda está dentro de uma visão amplamente referenciada na literatura das décadas de 70 e $80^{(27-29)}$, na qual havia uma preocupação de nível individual e quase descontextualizado do sistema familiar, circulando o foco de atenção em direção ao acompanhante, de modo isolado.

A equipe, na unidade pediátrica, observa que há diferenças de comportamento do familiar, frente ao tipo de doença e a fase da internação. Há ainda outras diferenças:

quem é daqui (da capital) e quem vem do interior. Os daqui se sentem mais em casa, reclamam mais. Os do interior são humildes, não perguntam, não tem experiência [...] agradecem por tudo (Enfermeira).

Tanto no olhar da equipe da unidade pediátrica como no alojamento, as crenças e práticas da família são, de forma geral, consideradas irrelevantes e são feitas tentativas de correção:

a maior dificuldade é que muitas mães não querem dar o banho, porque é frio ou porque não são de banho (Auxiliar de Enfermagem da unidade pediátrica);

não te preocupa é normal (frase comum da equipe do alojamento, quando as famílias questionam sobre algum fenômeno corporal apresentado pela criança ou pela puérpera).

A equipe de profissionais da unidade pediátrica olha o jeito do familiar acompanhante classificando-o em diferentes tipos, e a partir daí passa a desenvolver cuidados específicos e a decidir se reforça as normas de comportamento ou se as afrouxa. Há os folgados, que invadem espaços e opinam sobre os cuidados; as cuidadosas, consideradas aquelas mães que sabem das coisas, tendo o discernimento sobre quando falar e calar e cuidam bem da veia. Em oposição a estas, existem as descuidadas, para as quais a equipe precisa dar em cima. A condição dos membros da família da criança internada é enquadrada pela equipe em um perfil psicológico frágil; são estressados ou nervosos:

uns são estressados, são mais doentes que os filhos (Auxiliar de Enfermagem).

A equipe entende que o familiar que sofre com a doença tem também um tipo de doença, o estresse. O familiar estressado questiona sobre a doença e os cuidados, sendo que alguns componentes da equipe, principalmente os da enfermagem, têm diferentes reações diante do familiar estressado: ficam com medo, chamam a enfermeira, perdem a paciência, enfrentam, ou ainda, ignoram.

De forma muito semelhante, no alojamento conjunto, a equipe também classifica os tipos de mães: as que colaboram, como sendo aquelas que não atrapalham o andamento da unidade e que cuidam bem de seus filhos, estando portanto, numa condição de boa paciente, dentro do modelo biomédico e como sendo aquela que cumpre o que a equipe espera e que não perturbe ${ }^{(30)}$. As rebeldes da unidade de alojamento têm semelhança com as descuidadas e as folgadas da unidade pediátrica, uma vez que demonstram seu descontentamento acerca das regras e ensinamentos sobre o cuidado, e a equipe considera que atrapalham o dia-a-dia da unidade. Há ainda as resistentes que dissimulam o descumprimento das regras de cuidado e são consideradas $d i$ fíceis de lidar. No alojamento há ainda as que têm dificuldades de serem mães ou as especais, por possuírem dificuldades específicas para cuidarem de si ou da criança recémnascida. Estão dentro desta categoria as que perderam seus filhos, as portadoras de HIV e com crianças malformadas. São com estas que a equipe vivencia o que denomina como situações de estresse, por desconhecerem a forma de abordagem e de cuidados. 
Sobre esta visão das equipes, podemos resgatar estudos que aludem às instituições totais ${ }^{(25)}$, em que as equipes dirigentes desenvolvem uma versão funcionalista da vida moral em miniatura, uma espécie de teoria da natureza humana, o que dá meios sutis para manter a distância social com relação aos internados e uma visão estereotipada deles. Geralmente a teoria abrange as possibilidades boas e más das condutas dos internados, justificando privilégios ou castigos, conforme o caso. Desta forma, nas duas unidades de internação onde transitam famílias com crianças, parece haver uma moral do dever familiar de cuidado. Tudo gira ao redor do cuidar bem/cuidar mal. Mesmo quando apenas apontam as características dos familiares, estas estão ligadas às conseqüências do cuidado que podem prestar às crianças.

Por outro lado, em ambos os cenários assistenciais, seja na unidade pediátrica ou no alojamento conjunto, as famílias têm diante de si símbolos bastante confusos de identificação dos diferentes integrantes da equipe de enfermagem e da equipe de saúde, uma vez que todos os que ali trabalham vestem roupas brancas e têm atitudes profissionais parecidas. Esta dificuldade é ainda agravada pelo grande número de integrantes da equipe profissional que circula nas dependências das unidades. Assim, na dúvida, quase sempre se referem aos integrantes da equipe como sendo $d a$ enfermagem e, por ser a maioria, mulheres, as denominam simplesmente por Elas ou por Enfermeiras.

O nome às vezes não é tão importante para que a família se aproxime ou se afaste de determinados membros da equipe; outros atributos são essenciais para estabelecer ou não confiança e aproximação: tem umas que são boazinhas, e outras nem tanto, um eufemismo para evitar dizer palavras mais duras. Boazinhas são as integrantes da equipe que relativizam as normas e rotinas, que escutam e que estão dispostas ao diálogo. São também as que se esforçam para se colocarem na situação do familiar. Nem tanto são aquelas que no alojamento, diante de uma pergunta, logo respondem de forma padronizada: ah, isto é normal, sem realmente escutarem os argumentos que a família expõe. As que estão nesta categoria são as que não consideram que existe um saber familiar relacionado à experiência com o evento do nascimento e que focalizam a biomedicina como o único conhecimento válido. As integrantes da equipe consideradas pelas famílias como nem tanto, na unidade pediátrica, são aquelas que mandam, implicam e advertem os familiares. Em ambas as unidades as nem tanto são aquelas que dificilmente negociam, correndo em mundos paralelos. Visto sob este prisma interpretativo, as unidades de internação constituem-se num local complexo, no qual fronteiras simbóli$\operatorname{cas}^{(31)}$ são delineadas. As famílias, assim, do mesmo modo como procedem as equipes, estabelecem fronteiras que ajudam a se aproximarem ou a se afastarem dos profissionais e a se adequarem ou relutarem frente às regulamentações institucionais.

\section{CONSIDERAÇÕES FINAIS}

Os dados coligidos e interpretados a partir do método comparado permitem concluir que as equipes de ambas as unidades de internação sob análise, ainda que já estejam iniciando o vislumbramento da família como um elemento que se insere cada vez mais forte e influente no meio hospitalar, continuam a se posicionarem e a se relacionarem diante do acompanhante; e não propriamente da família como um sistema de cuidado. As equipes ainda não conseguiram fortalecer a idéia de que a família é uma unidade que cuida de si e possui demandas e necessidades específicas no contexto hospitalar ${ }^{(32)}$. O mesmo enfoque interpretativo também permite assinalar que, embora as equipes deparem-se, cotidianamente, com estruturas familiares bastante diversificadas, ainda têm resistências em reconhecerem e perceberem as necessidades singulares de tais estruturas e dinâmicas, e acabam reforçando então o modelo de família nuclear.

Os resultados mostraram que as duas unidades de internação possuem características que as demarcam como instituições totais ${ }^{(24)}$, já que ambas possuem uma lógica de funcionamento que dá ênfase à ruptura entre o mundo externo e o mundo dos internados. A entrada neste mundo dos internados é diferenciada nas duas unidades estudadas, o que de certa forma está em consonância com as características de cada uma, ou seja, a alta rotatividade da maternidade proporciona ênfase na massificação das orientações de admissão, enquanto que na unidade de internação pediátrica a perspectiva do cliente é de permanecer mais tempo, o que leva a possibilidade de que tais orientações sejam fornecidas progressivamente. Outra característica compatível com a instituição total é a de que os procedimentos em saúde são quase sempre demarcados por regras, circunstâncias regimentais e padronizações de rotinas que ligam os usuários aos domínios da instituição, marcando, ao menos temporariamente, suas exclusões do mundo exterior. $\mathrm{O}$ momento da alta também é circunscrito em normas e condições de saída que, analisadas à luz da instituição total, deixam claro que somente após serem cumpridas, tornam as famílias 'aptas' a deixarem o hospital. Portanto, estar sob o domínio da instituição total leva tanto a equipe a ver a família, como a família a ver a equipe, dentro de alguns padrões seletivos e norma-tivos, cujo enquadre entre o bem e o mal - como valores de julgamento moral - ajuda a manter a fronteira entre o mundo da equipe $\mathrm{e}$ o mundo da família.

Do ponto de vista da permanência das famílias nas unidades, observa-se que há micro-resistências, traduzidas pelo burlar silencioso de inúmeras regras impostas, como comer nos quartos, alongar o horário da visita, ou mesmo entrar na rouparia quando ninguém está olhando. Além disso, aparecem resistências de caráter coletivo mais amplo como as que foram identificadas nas duas unidades em estudo, denominadas como redes de solidariedade. Estes fenômenos, tão pouco estudados em nossas pesquisas, merecem maior apro- 
fundamento teórico para a sua compreensão. O apoio que ocorre entre os familiares cuidando de si e de seus filhos internados deve ser mais bem investigado a fim de que possa vir a tornar-se uma importante estratégia contra o peso massificante da instituição total. Da mesma forma, nos programas de humanização já em curso em inúmeras instituições de saúde, deveria se reconhecer e fortalecer estas redes, na intenção de contribuir para o mesmo objetivo.

Os resultados mostram também que é possível vivenciar a internação hospitalar como um evento de crescimento mútuo, mesmo que seja dentro do cenário clínico. As fronteiras institucionais que histórica e hegemonicamente se fecham para as experiências subjetivas da família e se abrem para o prescrito e o normatizado, podem ter suas margens afrouxadas e apresentar maior capilaridade entre o setor profissional e o setor familiar, mesmo que isto ainda se constitua em pequenas, mas significativas brechas assistenciais, somente visíveis quando garimpamos as minúcias do cuidado localizado, muitas vezes, na periferia da assistência.

\section{REFERÊNCIAS}

1. Perlini NMOG, Faro ACM. Cuidar de pessoa incapacitada por acidente vascular cerebral no domicílio: o fazer do cuidador familiar. Rev Esc Enferm USP. 2005;39(2):154-63.

2. Colvero LA, Ide CAC, Rolim MA. Família e doença mental: a difícil convivência com a diferença. Rev Esc Enferm USP. 2004;38(2):97-205.

3. Hoga LAK. A dimensão subjetiva do profissional na humanização da assistência à saúde: uma reflexão. Rev Esc Enferm USP. 2004;38(1):13-20.

4. Souza AIJ, Ribeiro EM, Eckert ER. Dialogando com a equipe de enfermagem sobre necessidades educativas dos acompanhantes de crianças internadas: construindo caminhos para o cuidado à família. Texto Contexto Enferm. 2003;12(3):280-8.

5. Marcon SS, Waidman MAP. A enfermagem frente a problemas de relacionamento na família. Rev Bras Enferm. 2003;56(3): 248-53.

6. Andrade GO, Marcon SS, Silva DMP. Como os enfermeiros avaliam o cuidado/cuidador familiar. Rev Gaúcha Enferm. 1997;18(2):123-32.

7. Guimarães CM, Ribeiro NRR. Convivendo com a doença do irmão. Rev Gaúcha Enferm. 1997;18(1):17-23.

8. Elsen I, Althof CR, Marques L. Modelos assistenciais utilizados nas unidades de internação pediátrica de hospitais de Santa Catarina-Brasil. Texto Contexto Enferm. 1993;2(1):33-52.

9. Boehs AE. Os movimentos de aproximação e distanciamento entre os sistemas de cuidado familiar e profissional [tese]. Florianópolis: Programa de Pós-Graduação em Enfermagem, Universidade Federal de Santa Catarina; 2001.
Esta pesquisa, motivada pela necessidade de aprofundar conhecimentos acerca da assistência à família na unidade de internação contribui com vários resultados que implicam, desde a necessidade de mudança nas instâncias de poder exercidas pelo hospital sobre a unidade familiar, até a importância de se colocar em debate a relação equipe de saúde e enfermagem/direitos das famílias, já que os significados impressos em muitas de suas atitudes relacionadas à inserção da família na unidade de internação, revelam valores que são excludentes, apesar de todo o avanço contrário que os próprios movimentos sociais têm alcançado no sentido da inclusão da família dentro do hospital, desde o momento do nascimento até a morte. Esperamos que esses resultados possam auxiliar no refinamento do debate acerca da atenção à família, contribuindo para aumentar a valorização e inserção desta no locus hospitalar.

10. Monticelli M. Aproximações culturais entre trabalhadoras de enfermagem e famílias no contexto do nascimento hospitalar: uma etnografia de alojamento conjunto [tese]. Florianópolis: Programa de Pós-Graduação em Enfermagem, Universidade Federal de Santa Catarina; 2003.

11. Geertz C. Nova Luz sobre a antropologia. Rio de Janeiro: Jorge Zahar; 2001.

12. Gómez-Camelo D. Análisis comparado de los sistemas de salud de la región andina y el caribe. Rev Salud Pública. 2005;7(3): 305-16.

13. Pliscoff CV, Monje PR. Método comparado: um aporte a la investigación em gestión pública. In: Temas presentados en el $8^{\circ}$ Congreso Internacional de CLAD sobre la Reforma del Estado y de la Administración Pública; 2002 nov. 28-31; Panamá. Panamá: CLAD; 2003. p. 28-31.

14. DaMatta R. Carnavais, malandros e heróis. $5^{\text {a }}$ ed. Rio de Janeiro: Guanabara; 1990.

15. Lincoln YS, Guba EG. Naturalistic inquiry. Newbury Park: Sage; 1985.

16. Peirano M. O dito e o feito: ensaio de antropologia dos rituais. Rio de Janeiro: Relume Dumará; 2002.

17. Spradley JP. Participant observation. Fort Worth: Harcourt Brace Jovanovich; 1980.

18. Leininger MM. Cultural care diversity and universality: a theory of nursing. New York: National League for Nursing Press; 1991. 
19. Conselho Nacional de Saúde. Resolução n. 196, de 10 de outubro de 1996. Dispõe sobre diretrizes e normas regulamentadoras de pesquisas envolvendo seres humanos. Bioética. 1996;4(2 Supl):15-25.

20. Carapinheiro G. Saberes e poderes no hospital: uma sociologia dos serviços hospitalares. $3^{\text {a }}$ ed. Porto: Afrontamento; 1998.

21. Goffmann E. Manicômios, prisões e conventos. $6^{\mathrm{a}}$ ed. São Paulo: Perspectiva; 1999.

22. Ketler SK. Preparing for motherwood: authoritative knowledge and the undercurrents of shared experience in two childbirth education courses in Cagliari, Italy. Med Anthrop Quart 2000;14(2):138-58.

23. Monticelli M. Nascimento como um rito de passagem: abordagem cultural para o cuidado às mulheres e recém-nascidos. São Paulo: Robe; 1997.

24. Maldonado MT. Psicologia da gravidez, parto e puerpério. $15^{a}$ ed. São Paulo: Saraiva; 2000. Aspectos psicológicos da gravidez, do parto e do puerpério; p. 114-30.

25. Wright L, Leahey M. Enfermeiras e famílias: um guia para avaliação e intervenção na família. $3^{a}$ ed. São Paulo: Roca; 2002.
26. Douglas SM. Como as instituições pensam. São Paulo: EDUSP; 1998.

27. Elsen I. Ações desempenhadas pelas mães durante a visita a seu filho hospitalizado [dissertação]. Florianópolis: Programa de Pós Graduação em Enfermagem, Universidade Federal de Santa Catarina; 1979.

28. Huerta EPN. Reflexões sobre o comportamento das enfermeiras perante as mães na unidade pediátrica. Rev Esc Enferm USP. 1984;18(3):209-14.

29. Schmitz EM. A enfermagem em pediatria e puericultura. São Paulo: Atheneu; 1989. A problemática da hospitalização; p. 181-96.

30. Kitzinger S. Mães: um estudo antropológico da maternidade. $2^{\mathrm{a}}$ ed. Lisboa: Presença; 1996.

31. Velho G. Individualismo e cultura. $5^{\mathrm{a}}$ ed. Rio de Janeiro: Jorge Zahar; 1999.

32. Imori MC, Rocha SMMR, Sousa HGLS, Lima RAGL. Participação dos pais na assistência à criança hospitalizada: revisão crítica da literatura. Rev Esc Enferm USP. 1997;10(3):37-43. 